\title{
FATIGUE ASSESSMENT OF FRICTION STIR WELDED DH36 STEEL
}

\author{
Athanasios Toumpis ${ }^{1}$, Alexander Galloway ${ }^{1}$, Helena Polezhayeva ${ }^{2}$, Lars Molter ${ }^{3}$ \\ ${ }^{1}$ University of Strathclyde; James Weir Building, 75 Montrose Street; Glasgow G1 1XJ, UK \\ ${ }^{2}$ Lloyd's Register EMEA; 71 Fenchurch Street; London EC3M 4BS, UK \\ ${ }^{3}$ Center of Maritime Technologies e.V.; Bramfelder Str. 164; D-22305, Hamburg, Germany
}

Keywords: Friction stir welding, Low alloy steel, Fatigue testing, Fracture surface

\begin{abstract}
A fatigue performance assessment of $6 \mathrm{~mm}$ thick friction stir welded DH36 steel has been undertaken, filling a significant knowledge gap in the process for steel. A comprehensive set of experimental procedures has been proposed; the consequent study extensively examined the weld microstructure, hardness, geometry and misalignments of the samples in support of the tensile and fatigue testing. The effect of varying weld parameters was also investigated.

The typical fatigue performance of friction stir welded DH36 steel plates has been established, exhibiting considerably extended fatigue lives, well above $10^{5}$ cycles at a stress range of $90 \%$ of yield strength, irrespective of minor instances of small surface breaking flaws which have been identified. An understanding of the way in which these flaws impact on the fatigue performance has been developed, concluding that surface breaking defects emanating from the friction stir tool's shoulder marks on the weld top surface can act as the dominant factor for crack initiation under fatigue loading.
\end{abstract}

\section{Introduction}

Recently, there has been a fair amount of progress in the development of the fundamental knowledge on friction stir welding (FSW) of steel. A prior publication [1] for instance has established an understanding of the link between the complex metallurgical system that FSW of DH36 steel produces and the resultant mechanical properties through microstructural characterisation and mechanical property testing, also expanding on the commonly applied welding speeds. However, one important mechanical property of steel friction stir welds, fatigue, requires to be investigated in more detail. Fatigue is considered to be the most important failure mechanism for steels; in particular, it is commonly quoted that fatigue accounts for almost $90 \%$ of the recorded mechanical service failures [2]. The fatigue life of welded components, where the weld itself contains process related flaws from which cracks can quickly initiate, even in the best quality welds, is commonly much reduced when compared to components that are unwelded. As one example, lack of weld penetration is widely reported as a highly detrimental feature in terms of fatigue life [3].

There is a growing number of publications for FSW of aluminium and other metals examining the materials' fatigue strength. Indicatively for aluminium, Ericsson and Sandstrom [4] investigate the effect of varying welding speed on the fatigue performance of friction stir butt welded high strength A16082. Although this aluminium focussed research employs only two welding speeds for FSW, thus limiting the value of the analysis, the fatigue strength of FSW is found to be practically unaffected by speed increasing within the industrially acceptable range [4]. A thorough study [5] on the FSW of stainless steel examines the fatigue behaviour of welded AISI 409M ferritic stainless steel with regard to the parent material (PM) properties. The original 
coarse PM grains are seen to be transformed by FSW into a refined ferrite / martensite banded structure of significantly higher hardness. The resultant dual phase microstructure is responsible for an improvement to fatigue life with regard to the PM; this is attributed to the superior tensile properties and an advantageous post-weld residual stress distribution [5].

Although material property data are gradually being generated for FSW of low alloy steel, the relevant publications evaluating its behaviour under fatigue loading are very limited; one noteworthy study [6] is evaluating the technical potential of FSW as a shipbuilding welding process and how it compares to submerged arc welding (SAW) of DH36 steel. An acicular shaped ferrite microstructure is observed in the thermo-mechanically affected zone (TMAZ), consistent over the mid-thickness of all FSW samples, whereas SAW samples present a typical acicular ferrite microstructure defined around proeutectoid ferrite grains [6]. The SAW plates present substantially more distortion than the FSW plates of the same thickness, and impact toughness levels for FSW and SAW samples are similar and within classification society impact requirements. A relatively limited fatigue testing programme demonstrates that FSW samples exhibit better fatigue performance than the SAW samples of equivalent thickness [6].

Due to the significance of a solid understanding of the fatigue behaviour in the wider acceptance of the process on steel and the lack of pertinent studies on low alloy steel, a detailed and extensive fatigue testing programme of FSW of steel grade DH36 was undertaken and is reported herein. This novel programme assesses the fatigue behaviour of FSW by testing a statistically broad number of samples in constant amplitude uniaxial tensile loading and generating the S-N (stress-life) curve, also characterising the weld microstructure and analysing the fatigue samples' fracture surfaces. Since fatigue performance is a critical design requirement in most cyclically loaded structures as in shipbuilding and other transportation systems, the findings are expected to further support the case for FSW of steel in a wider industrial environment.

\section{Experimental procedures}

Steel grade DH36 plates with original dimensions of $2000 \mathrm{~mm}$ x $200 \mathrm{~mm}$ and of $6 \mathrm{~mm}$ thickness were butt welded together at three traverse speeds $(100,250 \& 500 \mathrm{~mm} / \mathrm{min})$ by The Welding Institute (TWI Yorkshire) using a WRe-pcBN FSW tool. These welding speeds were selected as representative of the welding speeds explored in a previous study [1]. The specific preparation stages, i.e. sectioning, machining and polishing of the fatigue and tensile test samples adhered strictly to BS 7270 [7], and their basic dimensions are illustrated in Figure 1. The samples' sides were polished longitudinally to diminish the contribution of any transverse machining marks to the fatigue performance; still, the samples' top and bottom surfaces were tested in the "aswelded" condition. Since there are no internationally accepted standards for the testing and assessment of welded components under fatigue, a comprehensive and detailed experimental procedure for the fatigue assessment of FSW of steel was employed and is outlined below:

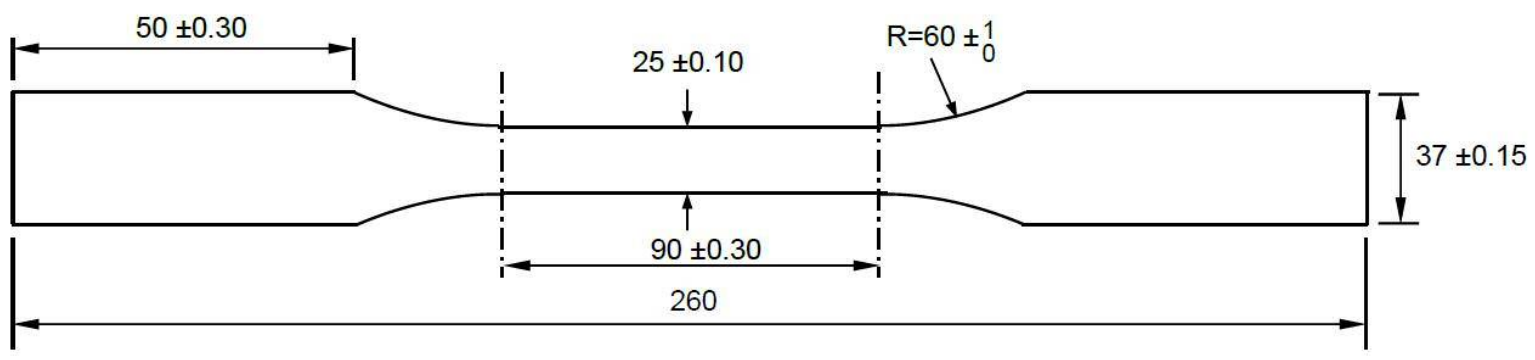

Figure 1. Transverse fatigue and tensile test sample of rectangular cross section (6 mm thick). 
- Metallographic examination, to assess the quality of each weld and correlate the observed microstructure to its fatigue performance.

- Hardness measurements, recorded for several positions which were deemed representative of the weld zone, consistently for all three welds.

- Geometry and misalignment measurements; clamping on the fatigue testing machine and consequent axial loading of a sample incorporating such irregularities can induce tensile or compressive stresses on any surface breaking flaws, thus accelerate or hinder any cracks which may initiate from these. Hence, possible irregularities on the samples were measured using strain gauges installed on both sides of three fatigue samples for each stress range by employing a precise and detailed procedure, and a coordinate measuring machine (CMM) to determine the samples' top surface geometry and likely weld misalignment.

- Tensile testing; three samples per weld were subjected to transverse tensile testing in order to identify the yield strength (YS) of the weldment. The trend reported in the previous work [1] was confirmed in this study; all slow and intermediate weld samples fractured in the PM, i.e. the weld exhibits higher tensile strength than the PM, while the fast weld samples fractured in the advancing (AD) side of the weld. The average YS value from the three intermediate weld samples, which was used for calculating all welds' fatigue testing parameters is $382 \mathrm{MPa}$.

- Fatigue testing was carried out on an Instron 8802 fatigue testing system. A large number of samples were tested for three welding speeds, with the emphasis placed on the intermediate welding speed (samples tested for three stress ranges, i.e. $70 \%, 80 \%$ and $90 \%$ of YS). The selection of appropriate stress ranges was informed by trial tests which were initially performed, commencing with stress range of $80 \%$ of YS. The effect of varying welding parameters was established by testing samples from the slow and fast speed welds at one stress range ( $80 \%$ of YS) and comparing these results with the basic S-N curve of the intermediate weld. The main variables of each stress range that was tested are summarised in Table I. The stress ratio was maintained equal to 0.1 and the stress frequency was kept constant at $10 \mathrm{~Hz}$ during the testing programme. The actual stresses attained by the testing machine vary insignificantly from the calculated values (no more than $0.1 \%$ ).

Table I. Summary of calculated values of the fatigue testing main variables

\begin{tabular}{|c|c|c|c|c|c|c|}
\hline \multirow[t]{2}{*}{ Weld speed } & \multicolumn{2}{|c|}{ Stress range } & \multirow{2}{*}{$\begin{array}{c}\text { Maximum } \\
\text { stress } \\
\sigma_{\max }(\mathrm{MPa})\end{array}$} & \multirow{2}{*}{$\begin{array}{c}\text { Minimum } \\
\text { stress } \\
\sigma_{\min }(\mathrm{MPa})\end{array}$} & \multirow{2}{*}{$\begin{array}{c}\text { Mean } \\
\text { stress } \\
\sigma_{\mathrm{m}}(\mathrm{MPa})\end{array}$} & \multirow{2}{*}{$\begin{array}{l}\text { Amplitude } \\
\sigma_{\mathrm{a}}(\mathrm{MPa})\end{array}$} \\
\hline & $\%$ of YS & $\Delta \sigma(\mathrm{MPa})$ & & & & \\
\hline \multirow{3}{*}{ Intermediate } & 70 & 240.7 & 267.4 & 26.74 & 147.1 & 120.3 \\
\hline & 80 & 275.0 & 305.6 & 30.56 & 168.1 & 137.5 \\
\hline & 90 & 309.4 & 343.8 & 34.38 & 189.1 & 154.7 \\
\hline Slow & 80 & 275.0 & 305.6 & 30.56 & 168.1 & 137.5 \\
\hline Fast & 80 & 275.0 & 305.6 & 30.56 & 168.1 & 137.5 \\
\hline
\end{tabular}

\section{Microstructural evaluation}

The following nomenclature for the various weld zones is identical to the one presented in the earlier study [1]. The metallographic preparation of all samples was performed in a way that the AD side is seen on the left side of the images. A heterogeneous microstructure is exhibited by the weld at $250 \mathrm{~mm} / \mathrm{min}-300 \mathrm{rpm}$ (intermediate traverse speed); this consists of acicular shaped 
bainitic ferrite rich regions and ferrite predominant regions of either acicular shape or of random geometry (Figure 2a). The analysis in the prior publication [1] had reported identical phases and concluded that the heterogeneity of the microstructure does not affect the weld's mechanical properties. This has again been verified in the fatigue behaviour of the weld (see later). The microstructure differs towards the bottom and outer sides of the weld, shifting to predominantly refined ferrite grains of random geometry (Figure $2 \mathrm{~b}$ ). This image also features a non-metallic inclusion which appears to have created a discontinuity in the surrounding phase, i.e. a minor cavity. The top surface of the intermediate weld seems mildly uneven, indented by the shoulder's threads. There are a number of incomplete fusion paths, or laps [8] observed particularly on the top outer retreating (RT) side (Figure 2c), with entrapped and interconnected non-metallic inclusions in various stages of oxidation (seen in different shades of grey). These laps could provide crack initiation sites during fatigue testing. The weld root has been fully fused, and the microstructure of this region comprises recrystallized ferrite and pearlite.

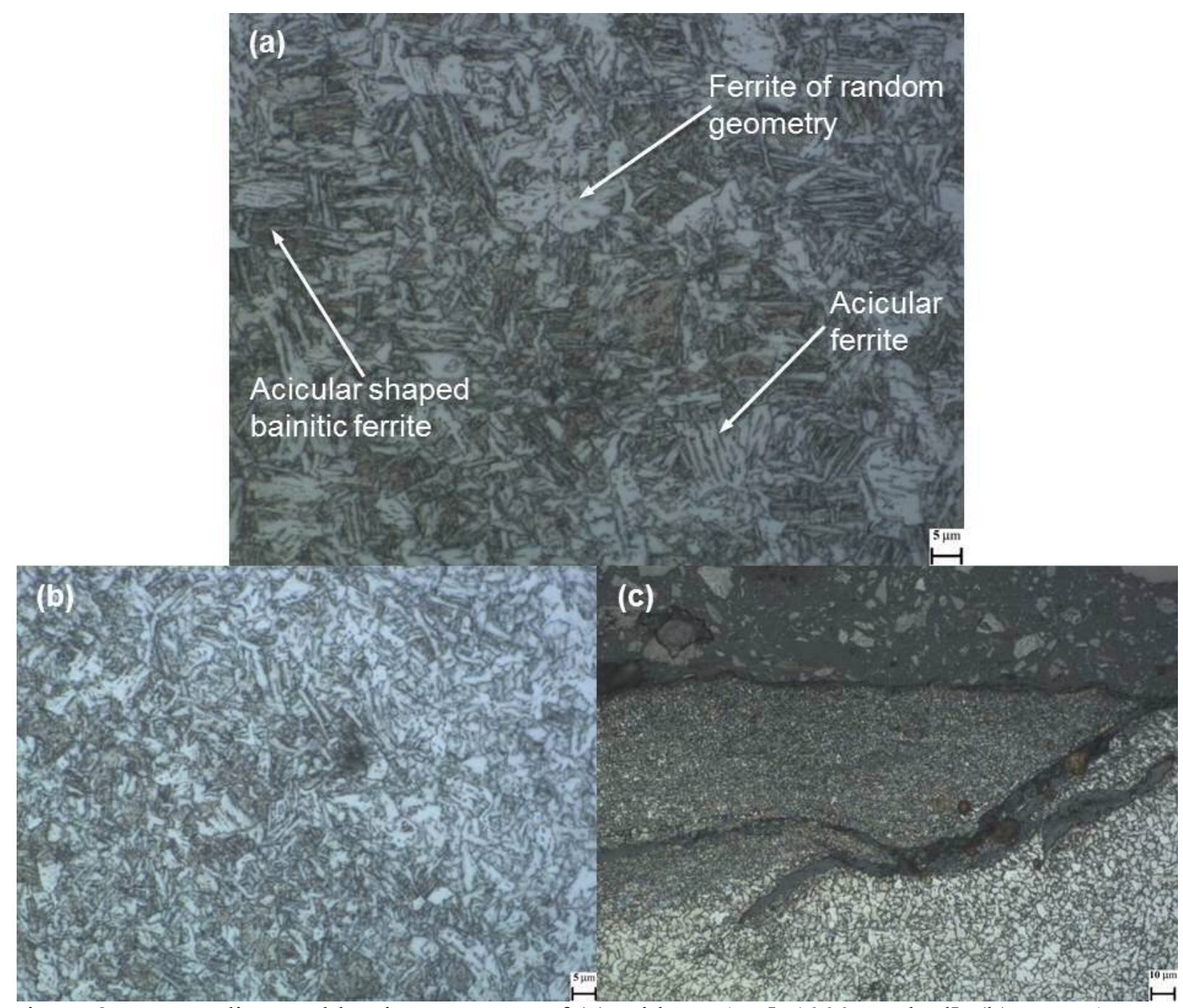

Figure 2. Intermediate weld, microstructure of (a) mid-TMAZ [x1000, Etched], (b) outer AD TMAZ [x1000, Etched] and (c) RT side top surface [x500, Etched].

The slow traverse speed weld $(100 \mathrm{~mm} / \mathrm{min}-200 \mathrm{rpm})$ presents a ferrite predominant homogeneous microstructure with significant grain refinement in comparison to the PM. The ferrite grains appear to be of random geometry, with minor traces of small acicular shaped grains (Figure 3). As expected for this mild set of welding parameters, no flaws are visible in the bulk 
of the TMAZ, the transition from the heat affected zone (HAZ) to the TMAZ is smooth, and the non-metallic inclusions introduced in the weld from the plates' surfaces are not completely mixed but remain interconnected.

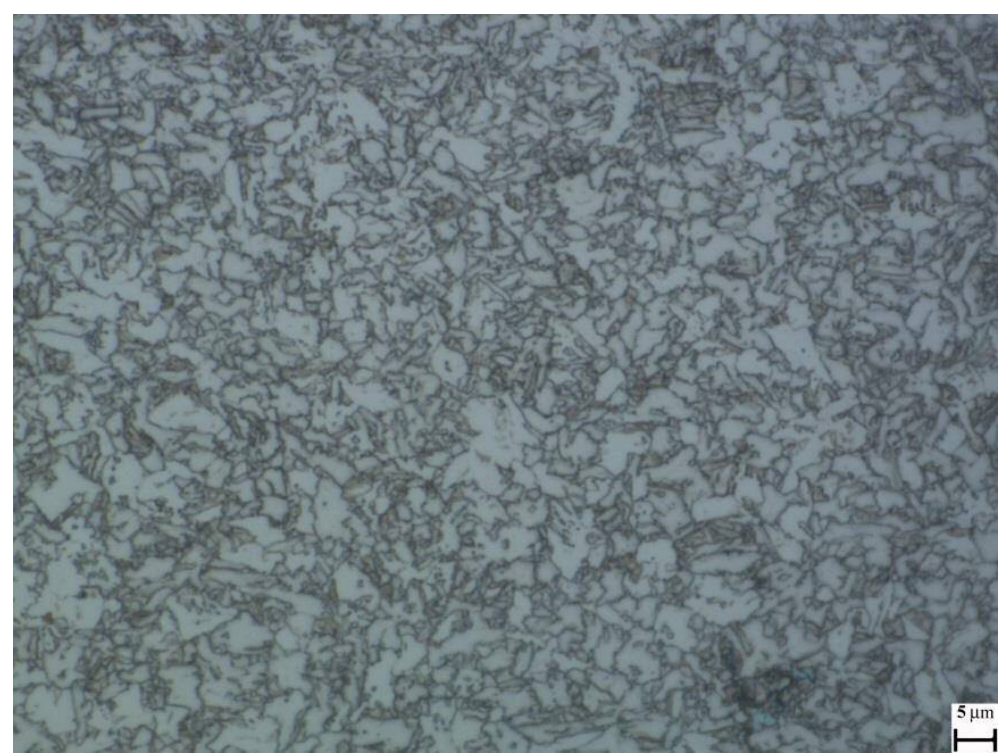

Figure 3. Slow weld, microstructure of mid-TMAZ [x1000, Etched].

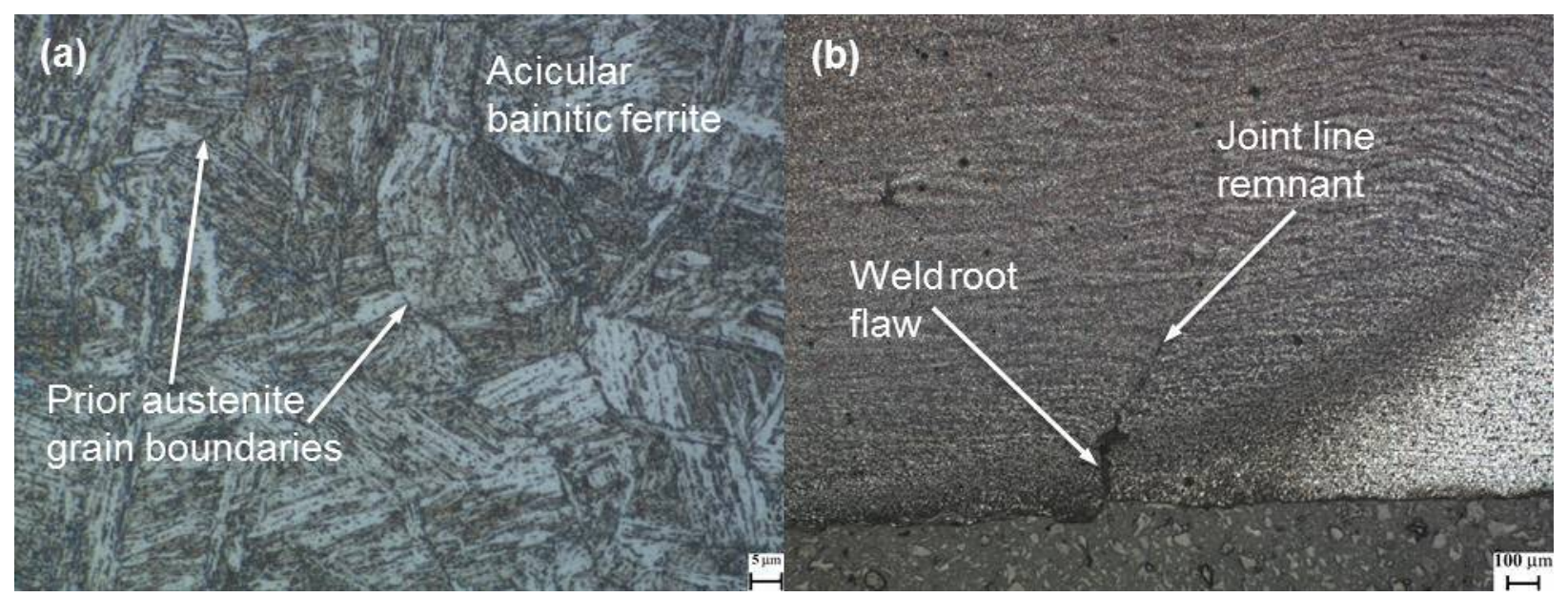

Figure 4. Fast weld, (a) microstructure of mid-TMAZ [x1000, Etched], (b) weld root [x50, Etched].

The fast traverse speed weld $(500 \mathrm{~mm} / \mathrm{min}-700 \mathrm{rpm})$ features what seems to be a predominantly acicular shaped bainitic ferrite microstructure with small regions of acicula ferrite; this is a fairly heterogeneous structure which should contain stress concentration regions (Figure 4a). The increased bainitic content is a direct consequence of the higher cooling rate due to the higher traverse speed of this weld. More, prior austenite grain boundaries are clearly detected (Figure 4a); acicular shaped grains appear to nucleate perpendicular to these boundaries. The weld presents an uneven top surface with marks on both sides corresponding to the tool shoulder's features. An apparently intermittent insufficient fusion at the weld root is seen to develop (Figure 4b). Since there is almost no stirring action of the tool's pin on the steel in this region, the thin film of non-metallic inclusions on the surface of the two plates being welded is not fully dispersed, thus forming a joint line remnant as an extension of the weld root flaw. 
Again, these are stress concentration regions which could provide crack initiation sites hence influence the weld's fatigue performance.

\section{$\underline{\text { Hardness distribution }}$}

The micro-hardness distribution for the three welds is presented in Table II, where the values are supplied as an average of two measurements per position. The hardness values follow the anticipated order; the hardness of the weld is seen to increase as the welding speed is increased. This is attributed to the increasing cooling rate that develops harder phases such as bainite. The microstructural examination above has noted the rise in the bainite content with each speed increment. Broadly, all welds appear harder than the PM but not at levels that can cause concern.

Table II. Micro-hardness (Vickers) measurements for the three weld speeds

\begin{tabular}{|l|c|c|c|c|c|c|c|c|}
\hline Weld & AD top & Mid-top & RT top & Mid-AD & Mid-TMAZ & Mid-RT & Weld root & PM \\
\hline Slow & 254 & 247 & 244 & 230 & 226 & 222 & 225 & 189 \\
Inter. & 254 & 257 & 247 & 266 & 265 & 247 & 240 & 169 \\
Fast & 280 & 303 & 318 & 306 & 355 & 356 & 250 & 184 \\
\hline
\end{tabular}

\section{Fatigue assessment}

The basic S-N curve for the fatigue life of the intermediate speed samples in the three stress ranges is presented in Figure 5. The ultimate fracture position for 19 out of the 20 tests performed on the intermediate weld was the weld's RT side. The fracture initiation sites are found to be the lap defects observed on this side's top surface. Still, all transverse tensile samples from the intermediate weld fractured in the PM; thus, excellent tensile properties do not necessarily predict the fatigue behaviour of a weld and certainly not the fracture position. The original aim of this study was to record fatigue lives within the range of $10^{5}$ to $2 * 10^{6}$ cycles.

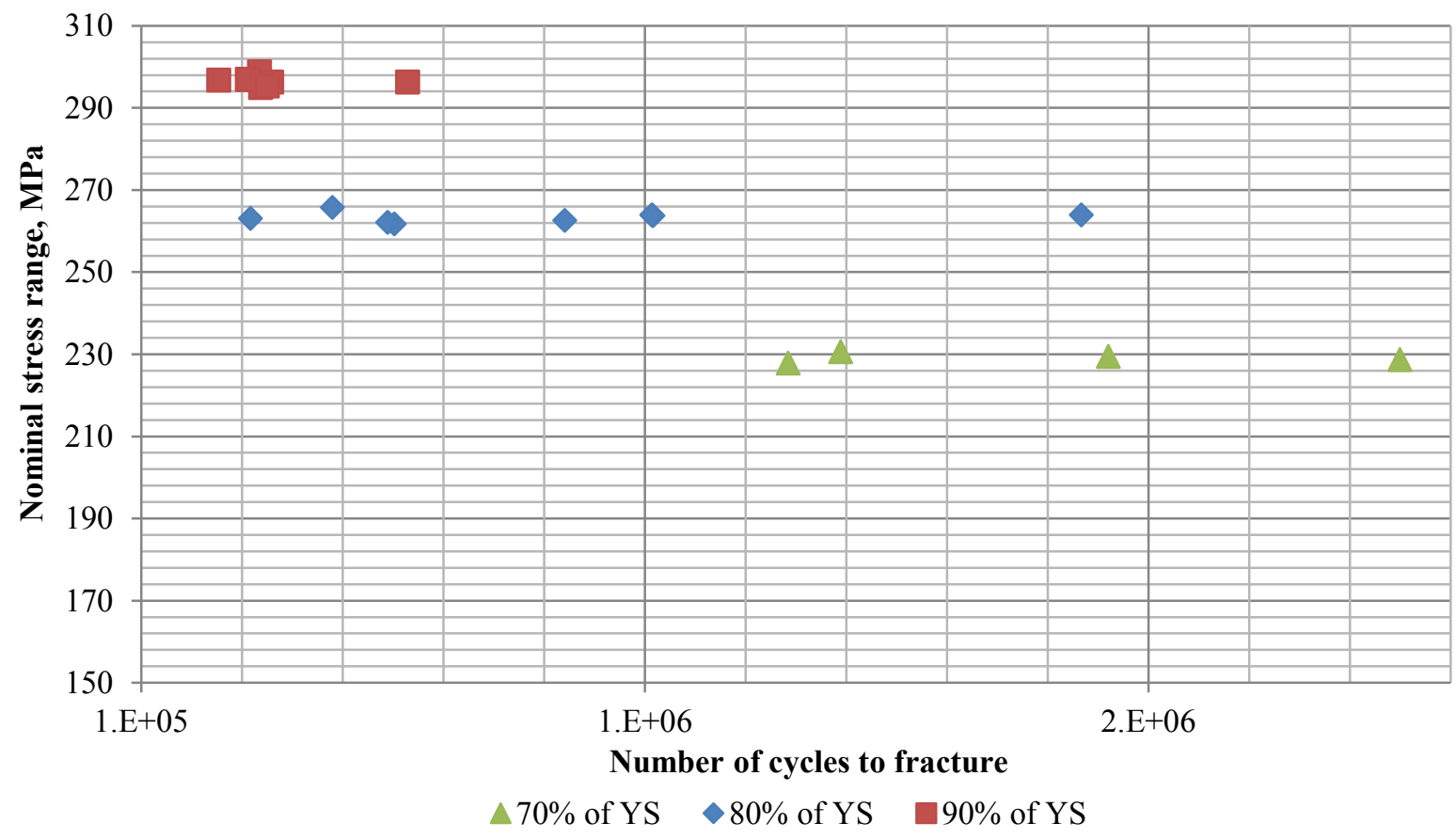

Figure 5. S-N curve for the intermediate weld. 


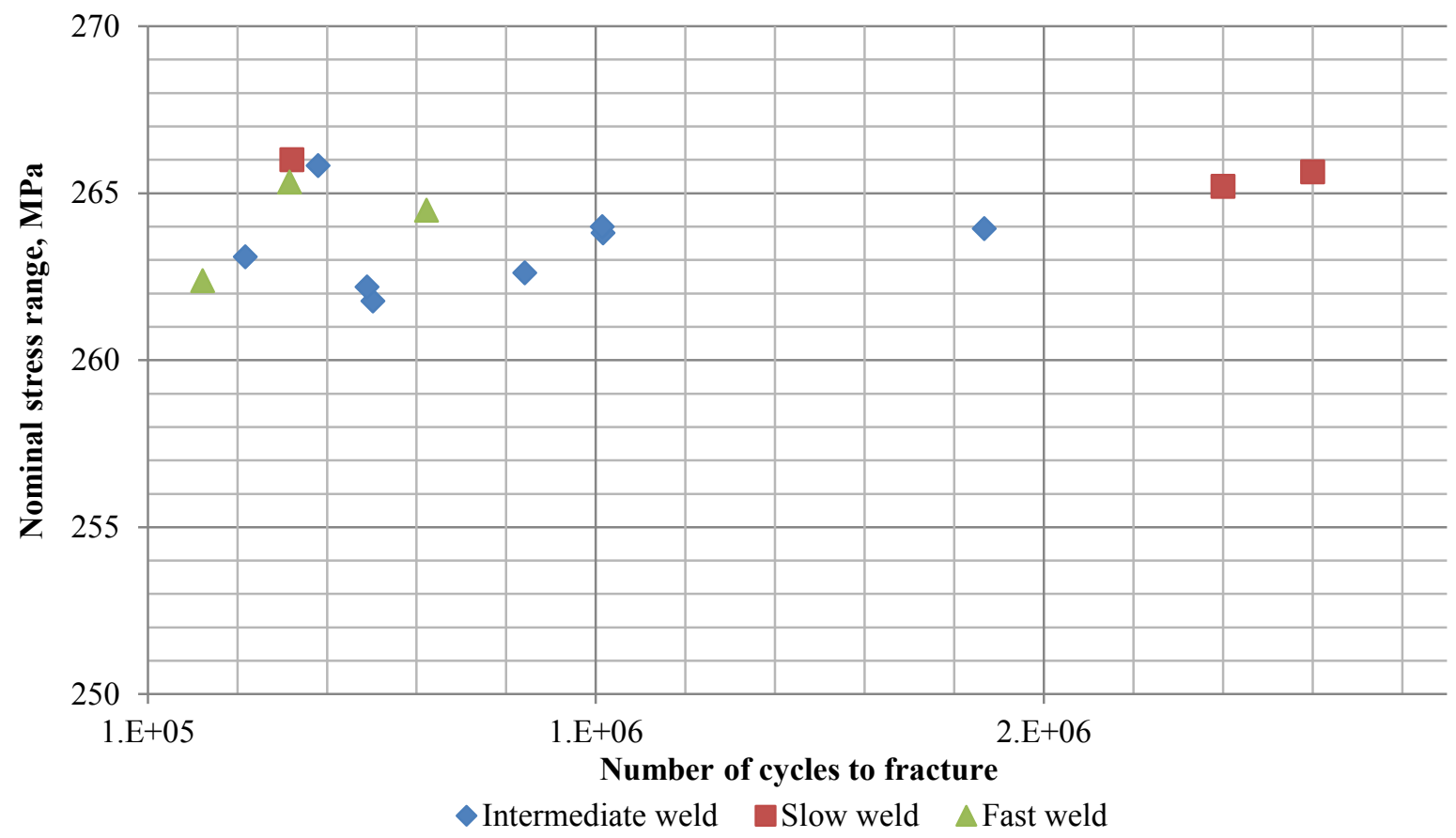

Figure 6. Fatigue test results for 3 welding speeds at $80 \%$ of YS.

The results present an excellent picture of the process on steel, with all tests reaching above $10^{5}$ cycles. One intermediate weld test was terminated before fracture since it reached $2.6^{*} 10^{6}$ cycles, far beyond the predetermined objective. The surface breaking flaws appeared to be much less pronounced in this region of the weld, thus did not initiate a crack of significant length within the duration of this test. The fatigue strength of this weld at $2 * 10^{6}$ cycles is $235 \mathrm{MPa}$ (Figure 5).

The fatigue test results for the slow and fast weld at $80 \%$ of YS are plotted in Figure 6 together with the intermediate weld results of the same stress range. Two samples of the slow weld exhibited excellent fatigue behaviour; the tests were terminated at $2.5^{*} 10^{6}$ cycles and above, and the samples displayed no evidence of crack initiation after testing. One sample fractured apparently prematurely at $4.2 * 10^{5}$ cycles (although higher than the lower limit of cycles that was set) on the AD side of the weld, and this is attributed to incomplete fusion paths observed on the weld top surface. The fast weld samples demonstrated rather mixed fatigue behaviour; all three samples recorded fatigue lives higher than $10^{5}$ cycles but with fairly scattered results, from $2.2 * 10^{5}$ to $7.2^{*} 10^{5}$, and contrasting fracture regions. Fracture initiated for two samples from the weld root flaw (Figure $4 \mathrm{~b}$ ) whilst the fracture initiation region for the third sample appears to correspond to the boundary between HAZ and TMAZ on the top AD side of the weld.

\section{Fracture surface analysis}

A systematic examination of the post-failure fracture surfaces has been performed. A recurrent pattern of fracture is observed in the intermediate weld samples; principally brittle fracture occurred on the outer RT side, with cracks initiating from this side's lap defects (discussed previously). For reporting purposes, two samples' typical fracture surfaces are presented herein as all the surfaces appear almost identical. Figure 7 features the two extreme cases in terms of number of cycles to fracture (lowest and highest) for the intermediate group tested at $80 \%$ of YS in order to enhance the fine differences from one sample to another. Figure $7 \mathrm{a}$ presents the 
sample that reached 317,472 cycles to fracture; uniform crack initiation from the FSW tool shoulder's markings on the top surface is indicated with arrows. Each of these sites includes many secondary which are seen as light of dark shaded hairline cracks. The other extreme, a sample from the same weld and fatigue testing group with 1,967,444 cycles to fracture is seen in Figure $7 b$, where crack initiation concentrated in one site. Fewer secondary hairline cracks appear to initiate from this area. Therefore, such localised crack initiation will take significantly longer to propagate through the entire cross-section of the sample.

This analysis has identified the markings produced by the FSW tool shoulder's features on the top surface of the weld (that is, a process-related feature) as the pivotal factor in fracture initiation during fatigue testing. The lap defect on the top RT side surface in particular, i.e. the incomplete fusion paths developed during FSW need to be tackled by further optimisation of the process parameters and improvements in the design and materials of the FSW tool for steel.

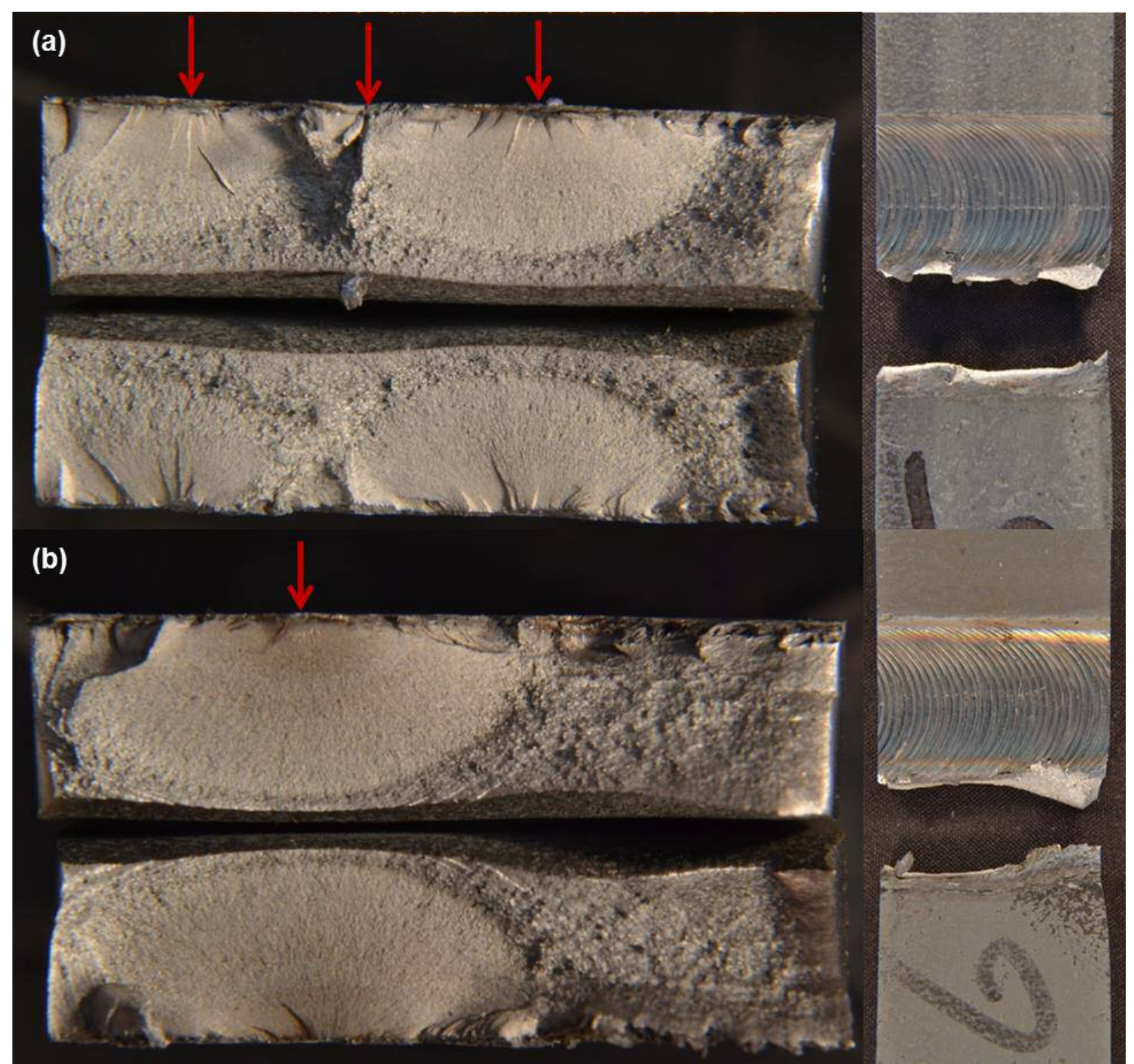

Figure 7 . Intermediate weld samples ( $80 \%$ of YS), (a) 317,472 cycles and (b) $1,967,444$ cycles. 


\section{Conclusions}

- A fully developed programme of fatigue assessment of $6 \mathrm{~mm}$ thick DH36 steel friction stir welds has been undertaken following a comprehensive set of experimental procedures, also accounting for the effect of varying welding speed.

- Steel friction stir welds have exhibited exceptional fatigue lives, well above $10^{5}$ cycles to fracture, even at a stress range of $90 \%$ of yield strength.

- An understanding of the relation between minor surface breaking weld flaws and the weld's fatigue performance has been established. The consistent fracture position has demonstrated that these almost negligible flaws can influence the fatigue life, justifying the need for full penetration welds and for addressing the tool shoulder's markings on the top surface.

- Tensile testing samples fracturing in the parent material and away from the weld proves that except for the yield strength, static loading does not carry important information on the steel's performance in real environments, where cyclic loading is the dominant stress mechanism.

\section{Acknowledgements}

The authors gratefully acknowledge the financial support of the European Union which has funded this work as part of the Collaborative Research Project HILDA (High Integrity Low Distortion Assembly) through the Seventh Framework Programme (SCP2-GA-2012-314534HILDA).

\section{References}

1. A. Toumpis, A. Galloway, S. Cater, and N. McPherson, "Development of a process envelope for friction stir welding of DH36 steel - A step change", Materials and Design, 62 (2014), 64-75.

2. Flake C. Campbell, ed., Elements of Metallurgy and Engineering Alloys (Materials Park, OH: ASM International, 2008).

3. Stephen J. Maddox, Fatigue Strength of Welded Structures, 2nd ed. (Cambridge, U.K.: Woodhead Publishing, 2002).

4. M. Ericsson and R. Sandstrom, "Influence of welding speed on the fatigue of friction stir welds", International Journal of Fatigue, 25 (2003), 1379-1387.

5. A.K. Lakshminarayanan and V. Balasubramanian, "Assessment of fatigue life and crack growth resistance of friction stir welded AISI 409M ferritic stainless steel joints", Materials Science and Engineering: A, 539 (2012), 143-153.

6. N.A. McPherson, A.M. Galloway, S.R. Cater, and S.J. Hambling, "Friction stir welding of thin DH36 steel plate", Science and Technology of Welding and Joining, 18 (5) (2013), 441-450.

7. British Standards Institution, "BS 7270:2006. Metallic materials - Constant amplitude strain controlled axial fatigue - Method of test" (London, U.K. 2006).

8. William T. Becker and Roch J. Shipley, eds., ASM Handbook, vol. 11 (Materials Park, OH: ASM International, 2002). 